\title{
Vagally Mediated Heart Rate Variability: A Risk Factor for Hypertension
}

\author{
Spyros Christou-Champi
}

Neuroapto Clinical and Applied Neuroscience Research and Development, Nicosia, Cyprus

\begin{abstract}
Hypertension is among the leading causes of mortality and an important contributor toward disability-adjusted life years worldwide. Several factors contribute toward individuals' risk to develop hypertension. Stress is considered an important pathogenic component affecting blood pressure regulation. However, systematic reviews examining the effect of psychosocial stressors and anxiety on hypertension produced spurious results. The observed heterogeneity in the operationalization of stress and subsequent reactivity hindered the characterization of the evidence for the association between exposure, physiological reactivity, and risk for hypertension. This is of paramount importance as physiological reactivity constitutes a biological interface mechanism through which stressors affect blood pressure regulation. The neural substrates of vagally mediated heart rate variability (VM$\mathrm{HRV}$ ) indicate that it is able to assimilate such an interfacing mechanism. Large-scale epidemiological studies provided substantial evidence linking decreases in VM-HRV with the development and progression of hypertension, indicating that individuals' reactivity to stressors, as measured via VM-HRV, increases individuals' risk for the development and progression of hypertension. As such, VM-HRV can reinforce current screening initiatives and support treatment-related prognosis. Self-regulation techniques, like heart rate variability biofeedback (HRVB), and neuromodulation techniques, like cranial electrotherapy stimulation (CES), are able to enhance VM-HRV and the associated parasympathetic modulation of cardiovascular outcomes, and thus address autonomic imbalances associated with hypertension.
\end{abstract}

Keywords: stress; central autonomic network; hypertension; heart rate variability; biofeedback; cranial electrotherapy stimulation

Citation: Christou-Champi, S. (2021). Vagally mediated heart rate variability: A risk factor for hypertension. NeuroRegulation, 8(3), 173-182. https://doi.org/10.15540/nr.8.3.173

*Address correspondence to: Spyros Christou-Champi, PhD, MBPsS, BCN, Neuroapto Clinical and Applied Neuroscience Research and Development, G.Kranidioti Av, 2235, Nicosia, Cyprus. Email: neuroblis@secretary.net

Copyright: (c) 2021. Christou-Champi. This is an Open Access article distributed under the terms of the Creative Commons Attribution License (CC-BY).

\author{
Edited by: \\ Rex L. Cannon, PhD, SPESA Research Institute, Knoxville, \\ Tennessee, USA
}

\section{Reviewed by:}

Randall Lyle, PhD, Mount Mercy University, Cedar Rapids, lowa, USA

Rex L. Cannon, PhD, SPESA Research Institute, Knoxville, Tennessee, USA

\section{Introduction}

Despite steady improvements in global health, hypertension remains a leading cause of mortality, especially in upper-middle and high-income countries, and an important contributor toward disability-adjusted life years worldwide (Vos et al., 2020). This is not surprising given hypertension's association with stroke and ischemic heart disease (Boehme et al., 2017; Špinar, 2012; Wajngarten \& Silva, 2019), which are currently considered as the leading causes of mortality and disability-adjusted life years worldwide. Several factors are thought to contribute toward individuals' risk to develop hypertension with the interaction between genetic (Lynch et al., 2020), behavioral (Hu et al., 2004), environmental (Bruno et al., 2017), and psychosocial (Cuffee et al., 2014) factors seen as accounting for the majority of hypertension cases (Ornosa-Martín et al., 2020; Singh et al., 2015). On this basis, stress is seen as having a significant role in modifying the impact of genetic factors on cardiovascular disease risk (Singh et al., 2015), and is considered an important pathogenic factor associating environmental stressors with high blood pressure as a result of maladaptation in various functional systems (Heine \& Weiss, 1987). 
Despite the well-documented link between the physiological bases of the stress response and blood pressure regulation, conclusions drawn from studies examining the relationship between exposure to psychosocial stressors and hypertension are hindered by the variability in the operational definitions used, and thus exposure to stressors and subsequent reactivity (i.e., initiation of the stress response; Player \& Peterson, 2011; Sparrenberger et al., 2009). Given the variability in stressors and reactivity measures employed in studies examining the impact of psychosocial stressors and anxiety, it is very difficult to summarize the evidence for the association between a welldefined characterization of exposure to stressors, subsequent physiological reactivity, and hypertension (Liu et al., 2017; Mann, 2012).

The aforementioned is of particular importance as physiological reactivity constitute a prominent biological mechanism through which stressors impact blood pressure regulation and thus affect health (Brown et al., 2018). Indeed, individuals' reactivity to stressors matters more than mere exposure to it, especially when examining stressors' impact on health (Crosswell \& Lockwood, 2020).

The present paper will initially discuss the role of stress in the regulation of blood pressure before examining the physiological mechanisms that allow vagally mediated heart rate variability (VM-HRV) to interface exposure to stressors with physiological reactivity. From there, it will discuss a substantial corpus of evidence linking VM-HRV with the development and progression of hypertension. Finally, it will examine self-regulation and neuromodulation techniques that can influence VMHRV, and thus improve individuals' physiological reactivity to stressors and autonomic imbalances associated with the development and progression of hypertension.

\section{The Physiology of the Stress Response}

Stress in physiology is seen as reflecting an organism's response to environmental pressures or demands (Selye, 1956). A system of interrelated brain structures regulating physiological arousal support stress responses. The central autonomic network (CAN) consist of both cortical areas including the insular cortex, anterior cingulate cortex, ventromedial prefrontal cortex (vmPFC), and subcortical structures like the central nucleus of the amygdala (CeA), hypothalamus, midbrain periaqueductal gray matter, parabranchial nucleus in the pons and medulla, nucleus of the solitary tract, ventrolateral reticular formation, and raphe nuclei
(Benarroch, 1993). The CAN receives input from sensory processing areas regarding the external environment, as well as input from body organs regarding the physiological state of the body. These inputs, allow CAN to modify physiological arousal to accommodate for changes in the internal and external environment.

The amygdala nuclear complex is very important in the initiation of both the immediate, transient responses to stressors implemented through the sympathetic-adrenal medullary (SAM) axis, and delayed, prolonged responses carried out by the hypothalamic-pituitary-adrenal (HPA) axis. Within this framework, the $\mathrm{CeA}$ directly activates sympathetic rostral ventrolateral medullary (RVLM) neurons enhancing immediate SAM axis influence (Saha et al., 2005; Thayer et al., 2009). In addition, the $\mathrm{CeA}$ sends prominent projections to the hypothalamus which is involved in the activation of the sympathetic nervous system (SNS; LeDoux et al., 1988) via the HPA axis (Xu et al., 1999) and of the SAM axis via the paraventricular nucleus (PVN) that projects to RVLM (Badoer, 2001).

In essence, the $\mathrm{CeA}$, through its projection to the hypothalamus, influences the activity of the HPA and SAM axes initiating the mechanisms of physiological arousal (see Figure 1). Under stress, the hypothalamus secretes corticotropin-releasing hormone $(\mathrm{CRH})$. This provokes the release of adrenocorticotropic hormone (ACTH) from the pituitary. ACTH stimulates the adrenal cortex which secretes mineralocorticoids and glucocorticoids (aldosterone/cortisol). The best characterized physiologic effect of aldosterone is to increase sodium reabsorption and potassium and hydrogen ion excretion in an effort to increase blood volume and pressure (Komesaroff et al., 1994). However, recent evidence pointed out that aldosterone also has a powerful vasoconstriction effect (Kushibiki et al., 2007). In addition, aldosterone evokes a fibrotic response in the myocardium, and a profibrotic, hypertrophic, and inflammatory response in the vasculature, where it also minimizes nitric oxide bioactivity, thereby hindering vascular relaxation (Briet \& Schiffrin, 2013). The abovementioned indicated that aldosterone is involved in the development of increased systemic vascular resistance and vascular and cardiac remodeling in a way that could sustain an elevated blood pressure (Freel \& Connell, 2004; Xanthakis \& Vasan, 2013). Cortisol has a pivotal role on metabolism as it prepares resources to provide energy through the catabolism of glycogen to glucose (Khani \& Tayek, 2001) and protein to amino acids (Brillon et al., 
1995). This helps to overcome the increased metabolic demand presented by the stressor.

Besides the abovementioned, the $\mathrm{CeA}$ and hypothalamically mediated SAM input stimulates the adrenal medulla, which secretes catecholamines (epinephrine/norepinephrine). SAM mediated release of epinephrine and norepinephrine has immediate effects on the cardiovascular systems.

Figure 1. Schematic Representation of CeA Influences on SAM (I \& II) and HPA (III) Axes.

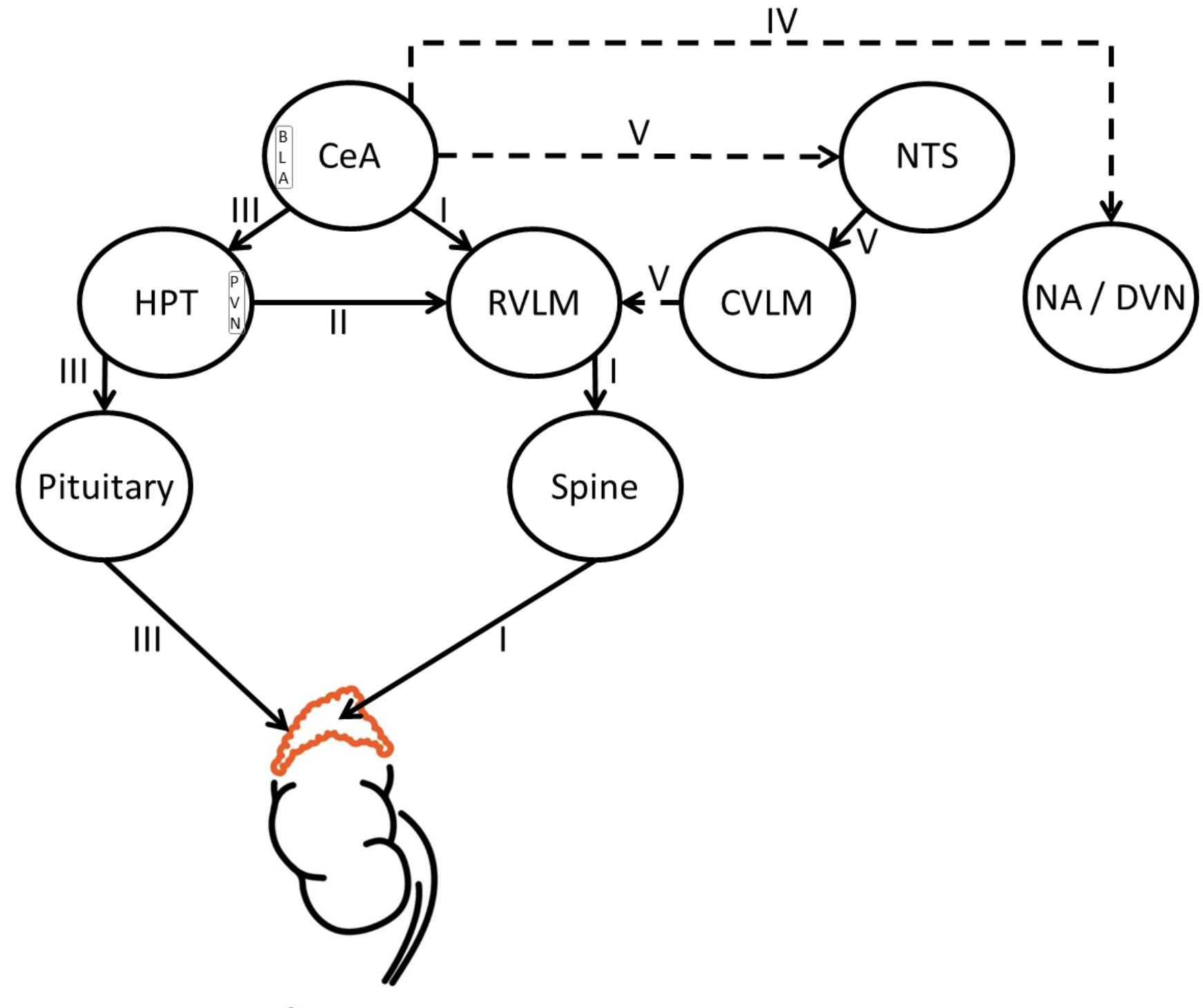

Note. Both the CeA (I) and the PVN (II) innervate the RVLM which is involved in the activation of the adrenal medulla, via the spinal cord. The adrenal medulla secretes epinephrine and norepinephrine triggering an immediate but transient response to stressors. Also, the CeA projects to HPT (III) which in turn innervates the pituitary. The stimulation of the pituitary gland activates the adrenal cortex which secretes aldosterone and cortisol into the bloodstream initiating a delayed but prolonged response to stressors. Besides that, CeA inhibits the activity of vagal motor neurons in the NA and the DVN (IV), and thus reduces parasympathetic input. Moreover, CeA minimizes the parasympathetic input of the NTS (V) which in turn reduces CVLM's inhibitory input to the sympathetic neurons of the RVLM. The inhibition of parasympathetic neurons and simultaneous disinhibition of sympathetic neurons lead to increases in physiological arousal. CeA: central nucleus of the amygdala; BLA: basolateral amygdala; SAM: sympathetic-adrenal-medullary axis; HPA: hypothalamic-pituitary-adrenal axis; PVN: paraventricular nucleus of the hypothalamus; RVLM: rostral ventrolateral medulla; HPT: hypothalamus; NTS: nucleus of the solitary tract; CVLM: caudal ventrolateral medulla; NA: nucleus ambiguous; DVN: dorsal vagal motor nucleus. 
Despite the vasodilation effect of low circulating epinephrine, high circulating concentrations shifts the balance of vasodilator and vasoconstrictor actions to net vasoconstriction (Klabunde, 2021). Similarly, norepinephrine increases cardiac output and systemic vascular resistance, resulting in an elevation in arterial blood pressure (Smith \& Maani, 2020).

Moreover, the $\mathrm{CeA}$ minimizes parasympathetic input by simultaneously inhibiting vagal motor neurons in the nucleus ambiguous (NA) and the dorsal vagal motor nucleus (DVN). Furthermore, the $\mathrm{CeA}$ inhibits the parasympathetic input of the nucleus of the solitary tract (NTS). This in turn, minimizes inhibitory caudal ventrolateral medullary (CVLM) inputs to the sympathetic neurons of the RVLM. The simultaneous disinhibition of sympathetic neurons, and the inhibition of parasympathetic neurons, leads to an increase in physiological arousal resulting in elevated heart rate (HR) and a concomitant decrease of VM-HRV.

All of these responses promote physiological arousal in an effort to facilitate an individual's ability to withstand the stressor experienced, and thus adapt and thrive in a particular environment. The brain monitors the levels of cortisol secreted and once these rise, it terminates the secretion of $\mathrm{CRH}$ and ACTH completing the stress response cycle (Harbuz \& Lightman, 1992; Tsigos \& Chrousos, 2002). This negative feedback loop is designed to limit long-term exposure to cortisol's catabolic and immunosuppressive actions (Guilliams \& Edwards, 2010).

Heart Rate Variability: Integrating Stressors and Physiological Reactivity

Physiological arousal responses, including increases in blood pressure, are governed by the sympathetic division of the autonomic nervous system (ANS) and the associated SAM and HPA axes. The reciprocal interconnection between CAN's neural structures allows the prefrontal cortex (PFC) to inhibit subcortical structures, and thus the individual to respond to environmental pressures or demands in an effective manner (see Figure 2). Indeed, the sympathetic output of the CAN is under tonic inhibitory control via prefrontal cortical areas, including the medial prefrontal cortex (mPFC) and the orbitofrontal cortex (OFC), that inhibit the amygdala via networks of gabaminergic neurons (Gianaros \& Wager, 2015; Shekhar et al., 2003; Thayer et al., 2009). Attenuation of PFC activity, via basolateral amygdala (BLA; Dilgen et al., 2013; Park et al., 2018), leads to disinhibition of the CeA that can directly activate the hypothalamus and sympathetic RVLM neurons.

Evidence from relevant research supports the role of the PFC in the control of sympathetic neurons within the CAN, and thus cardiac output. For example, the deactivation of the PFC via intracarotid administration of sodium amobarbital led to increases in HR and concomitant decreases in VMHRV (Ahern et al., 2001). Moreover, functional magnetic resonance imaging (fMRI) aiming to localize the central command network for induced cardiovagal activity indicated a positive correlation between VM-HRV and the dorsolateral PFC (Napadow et al., 2008). Likewise, fMRI paradigms examining the brain-heart interaction in a purely resting-state condition highlighted ventromedial PFC's role in the cortical generation of efferent vagal activity (Duggento et al., 2016; Ziegler et al., 2009).

Taken together, these evidences support the role of the PFC in the modulation of subcortical cardioacceleratory circuits via an inhibitory pathway that is associated with vagal function that can be indexed by VM-HRV. Within this context, VM-HRV signifies the extent of the deactivation of the PFC, and thus the disinhibition of CAN's sympathetic input. As such, VM-HRV integrates stressors with individuals' reactivity capturing a prominent biological mechanism through which stressors impact health.

Heart Rate Variability: Indexing Autonomic Imbalance and Hypertension

Lack of balance between the sympathetic and parasympathetic branches of the ANS minimizes the dynamic flexibility of the organism (Friedman \& Thayer, 1998). An autonomic imbalance in which typically the sympathetic system is hyperactive and the parasympathetic system is hypoactive is associated with various risk factors and pathological conditions (Thayer et al., 2010). HRV can be used to assess such autonomic imbalances. For example, various measures of HRV have been successfully used to assess vagal activity (Task Force of the European Society of Cardiology the North American Society of Pacing Electrophysiology, 1996). HRV measures in the time domain, including the standard deviation of $R$ to $R$ intervals (SDNN) and the root mean square successive differences (RMSSD), have been shown to be effective indices of vagal activity. Similarly, in the frequency domain, high frequency (HF: $0.15-0.40 \mathrm{~Hz}$ ) spectral power has been successfully used to index vagal activity. 
Figure 2. Schematic Representation of PFC Inhibitory Influence on the CeA.

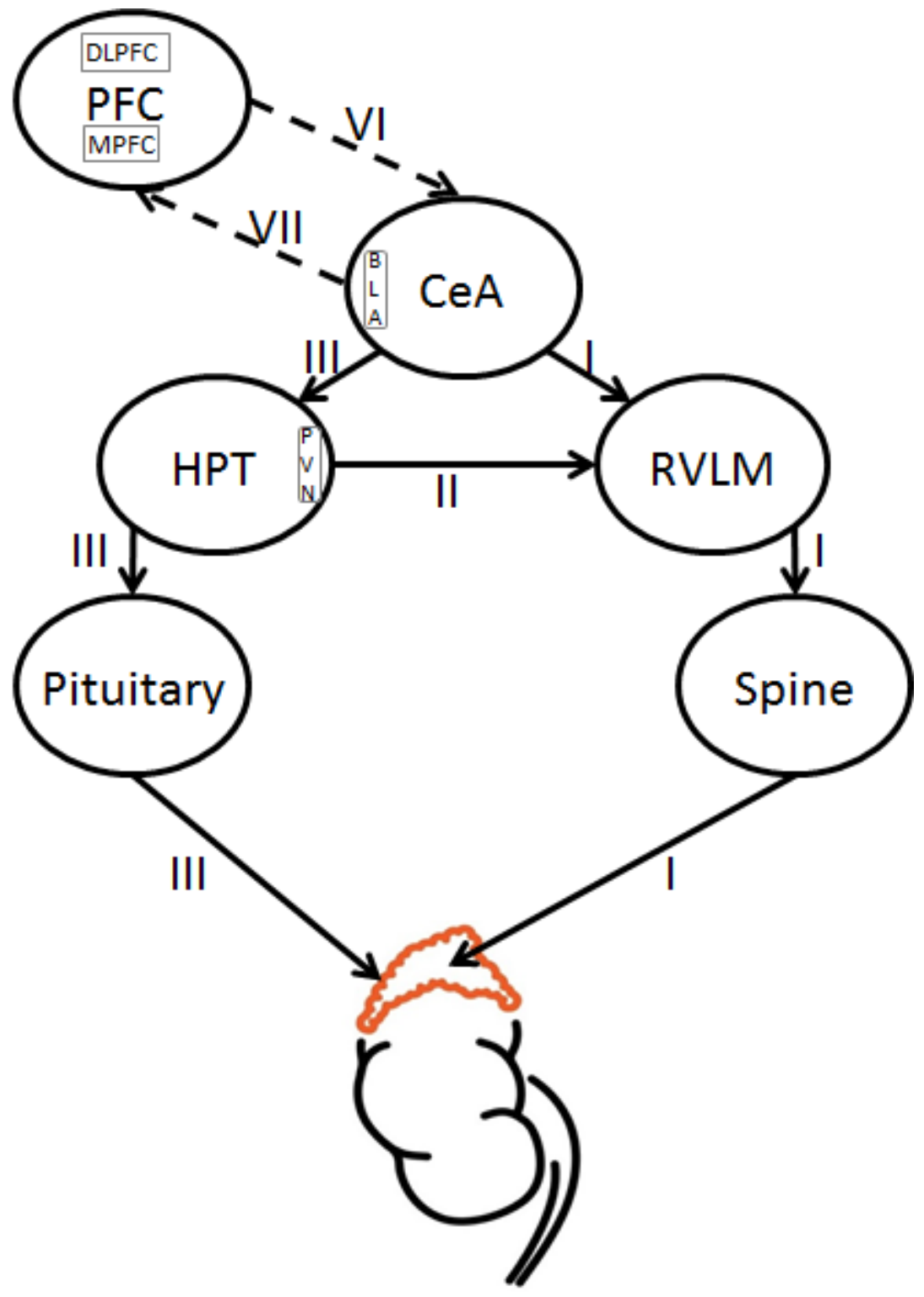

Note. The sympathetic output of the CeA is under tonic inhibitory control from the PFC (VI), including the mPFC and the OFC. The reduction of PFC's inhibitory input to the CeA as a result of the activation of the BLA (VII) leads to the activation of the SAM and HPA axes (CeA's influences on SAM and HPA axes, I to III, are described in Figure 1).

The relationship between autonomic imbalances and hypertension is documented in both cross-sectional and prospective studies. For instance, prospective studies that examined the association between two minutes of supine HRV and hypertension over a 3year follow-up period in a stratified random sample of 2061 black and white men and women from the Atherosclerosis Risk in Communities (ARIC) study reported an inverse relationship between HF-HRV and the development of hypertension (Liao et al., 1996). Those in the lowest HRV quartile had 2.44 greater risk of hypertension than those in the highest quartile. Additionally, cross-sectional analyses, adjusted for age, race, gender, smoking, diabetes, and education, indicated that the power of HF-HRV was significantly lower in both treated and untreated hypertensives compare to the normotensive group. Liao et al. (1996) results indicating that VM-HRV is 
lower in pharmacologically treated hypertensives compared to normotensives are in line with relevant research (Cowan et al., 1993; Mussalo et al., 2001). In addition, prospective analyses over longer followup periods that examined the relationship between RMSSD and hypertension in 7099 men and women from the ARIC study reported that the lowest quartile of HRV adjusted for age, race, study center, diabetes, smoking, education, and BMI was associated with a hazard ratio of 1.36 for the development of hypertension 9 years later, compared to those in the highest quartile (Schroeder et al., 2003). Consistent with Liao et al. (1996) and Schroeder et al. (2003), cross-sectional analyses showed that HRV adjusted for relevant covariates was lower at baseline among individuals with hypertension.

Likewise, cross-sectional analyses examining the association between 2 hours of ambulatory HR recordings and hypertension in men and women participating in the Framingham Heart Study reported significantly lower HRV in hypertensives than in normotensives after adjusting for age, BMI, smoking, and alcohol consumption (Singh et al., 1998). More recent cross-sectional examinations of the relationship between VM-HRV and hypertension utilizing 5-min supine recordings reported similar results suggesting significantly lower VM-HRV in individuals displaying high blood pressure compared to normotensive groups (Goit \& Ansari, 2016; Natarajan et al., 2014; Pal et al., 2011).

The aforementioned results from large-scale, prospective and cross-sectional epidemiological studies provide substantial evidence suggesting that decreases in parasympathetic input, as measured by VM-HRV, precedes the development of hypertension which is considered as the single most important risk factor for cardiovascular disease. In addition, these studies indicate that parasympathetic input, as indexed via VM-HRV, is lower in hypertensives than in normotensives even when these patients are treated with antihypertensive pharmacotherapy.

Addressing Autonomic Imbalances Associated with Hypertension

Self-regulation techniques, like heart rate variability biofeedback (HRVB), and neuromodulation techniques, like cranial electrotherapy stimulation (CES), have been successfully used to improve VM$\mathrm{HRV}$, and therefore autonomic imbalances which correlate with increased mortality and poor functional outcomes including elevated human arterial hypertension.
Heart Rate Variability Biofeedback

HRVB enables individuals to learn how to alter, and thus self-regulate, the variability and dominant rhythms of the cardiac function inducing beneficial adjustments in VM-HRV indices (Lehrer \& Gevirtz, 2014). For example, a recent randomized controlled trial pointed out that HRVB increased VM-HRV indices in acute ischemic stroke patients that displayed autonomic deregulation, including cardiac autonomic dysfunction compared to sham biofeedback (Siepmann et al., 2021). As expected, patients included in the active HRVB condition also benefited from significant reductions in autonomic symptoms. Such changes in observed indices of VM-HRV following HRVB are associated with enhancements in functional connectivity between CAN's neural structures exerting prefrontal control and those responsible for its sympathetic output. For instance, the resting state functional connectivity between vmPFC and the amygdala was strengthened following HRVB (Schumann et al., 2021).

Despite the aforementioned, systematic reviews examining the effects of HRVB on hypertension produced inconsistent results (Costa Vital et al., 2021; Greenhalgh et al., 2010; Nagele et al., 2014; Nakao et al., 2003). The majority of these studies reported high heterogeneity highlighting differences in interventions and inconsistencies in the measurement of outcomes observed that prevented the characterization of the evidence for the association between HRVB and hypertension.

One important aspect contributing to the observed heterogeneity is the preexisting and concurrent use of antihypertensive pharmacotherapy along HRVB interventions (Linden \& Chambers, 1994). This limits the potential effects of the HRVB intervention as the blood pressure levels of pharmacologically treated participants are often low when starting HRVB (McGrady, 2010). In support, randomized, double blind, placebo-controlled studies that included patients that had already been treated pharmacologically found no significant effect of HRVB on hypertension (Landman et al., 2013). On the contrary, randomized control trials that either included only unmedicated outpatients or statistically controlled for the effects of antihypertensive pharmacotherapy reported significant decreases in hypertension following HRVB compared to active control (Nolan et al., 2010; Palomba et al., 2011). In addition, studies examining the nature of cardiovascular reactions following HRVB suggested that this intervention is beneficial for patients treated with antihypertensive pharmacotherapy as it leads to 
pronounced reactivity of vagal mechanism (Poskotinova et al., 2013). This is of particular importance given that hypertensives treated pharmacologically still display significant decreases in VM-HRV compared to normotensives (Cowan et al., 1993; Liao et al., 1996; Mussalo et al., 2001).

Taken together, the abovementioned research findings pointed out that HRVB is able to increase indices of VM-HRV and enhance functional connectivity between CAN's neural structures exerting prefrontal control with those responsible for its sympathetic output. Such evidence suggested that HRVB is able to influence the neural mechanisms controlling blood pressure regulation. Given that the majority of patients with hypertension are already being treated pharmacologically, and having in mind that HRVB leads to pronounced reactivity of vagal mechanism even in patients treated pharmacologically, HRVB represents a promising intervention that should supplement pharmacotherapy. Besides this, patients with prehypertension may thus be the ideal population for HRVB, since their blood pressure is elevated, but not to a level that it would prompt the prescription of antihypertensive medication (McGrady, 2010).

\section{Cranial Electrotherapy Stimulation}

Noninvasive brain stimulation techniques, like CES, deliver low-intensity ( $50 \mu \mathrm{A}$ to $4 \mathrm{~mA}$ ) electrical current via electrodes attached to anatomical positions around the head to modulate the activity of the central and/or peripheral nervous system. Neuromodulation techniques can be an effective method to regulate the cardiovascular system given that noninvasive brain stimulation can influence autonomic imbalances that lead to hypertension (Cogiamanian et al., 2010). In point of fact, recent randomized, double blind, placebo-controlled trials reported significant increases in indices of VM-HRV following noninvasive CES as compared to sham CES (Altemus, 2019).

Likewise, randomized control studies examining the effect of CES on hypertension produced encouraging results supporting the use of noninvasive brain stimulation for the treatment of hypertension. For example, the early use of CES neuromodulation methods in hypertensive patients within a clinical pre-post paradigm resulted in an enhancement of parasympathetic modulation of cardiovascular outcomes and significant decreases in mean arterial blood pressure that stabilized within the normal range (Podzolkov et al., 1992). In addition, the preoperative administration of CES to hypertensive patients scheduled for surgery resulted in substantial (3-4 $\mathrm{mmHg})$, albeit statistically nonsignificant, decreases in arterial blood pressure (Kang et al., 2020). Moreover, a recent randomized controlled trial pointed out that CES leads to a significantly improved blood pressure profile via the regulation of systolic and diastolic blood pressure (Mohammadi et al., in press).

On the whole, studies examining the effect of CES highlighted its ability to improve VM-HRV and produced promising results regarding its use for the treatment of hypertension. However, the limited number of relevant studies accounting for the floor effect created by antihypertensive pharmacotherapy and the observed variation in CES interventions, including target sites, obscures CES's effect on hypertension. As such, further studies are necessary to elucidate the association between CES and hypertension.

\section{Conclusion}

The physiological substrates of the stress response, including prefrontal control, HPA, and SAM axes, support its role in the development and progression of hypertension. However, the examination of the relationship between exposure to stressors and hypertension was unsuccessful in confirming the underlying hypotheses in a decisive manner. Systematic reviews examining the effect of psychosocial stressors and anxiety on hypertension produced spurious results. The variability in the operationalization of stress and subsequent reactivity in these studies meant that relevant metaanalytic efforts suffered from strong heterogeneity that hindered the characterization of the evidence for the association between exposure, subsequent physiological reactivity, and risk for hypertension. This is of paramount importance as physiological reactivity to stressors constitutes a biological interface mechanism through which stressors affect blood pressure regulation.

The neural substrates of VM-HRV indicate that it is able to assimilate such an interfacing mechanism. In support, large-scale prospective and cross-sectional epidemiological studies provided substantial evidence linking decreases in VM-HRV with the development and progression of hypertension, hence indicating that individuals' reactivity to stressors, as measured via VM-HRV, amplify individuals' risk for the development and progression of hypertension. Within this context, VM-HRV can reinforce current screening initiatives in predicting future risk of hypertension and support treatment related prognosis. 
Self-regulation techniques, like HRVB, and neuromodulation techniques, like CES, are able to enhance VM-HRV, and therefore the parasympathetic modulation of cardiovascular outcomes, thereby addressing autonomic imbalances associated with hypertension. Relevant evidence suggested that HRVB should supplement pharmacotherapy in hypertensive patients and be considered as a first line treatment for prehypertension. Similarly, neuromodulation methods, like CES, produced promising results for the treatment of hypertension. However, further studies are needed to clarify the observed relationship between CES and hypertension.

\section{Author Declaration}

The author received no financial support for the research, authorship, and/or publication of this article.

The author declares no conflict of interest.

\section{References}

Ahern, G. L., Sollers, J. J., Lane, R. D., Labiner, D. M., Herring, A. M., Weinand, M. E., Hutzler, R., \& Thayer, J. F. (2001). Heart rate and heart rate variability changes in the intracarotid sodium amobarbital test. Epilepsia, 42(7), 912-921. https://doi.org/10.1046/j.1528-1157.2001.042007912.x

Altemus, M. (2019). Effect of cranial electrical stimulation (CES) on autonomic regulation. U.S National Library of Medicine. https://clinicaltrials.gov/ct2/show/results/NCT02163967

Badoer, E. (2001). Proceedings of the Australian physiological and pharmacological society symposium: The hypothalamus hypothalamic paraventricular nucleus and cardiovascular regulation. Clinical and Experimental Pharmacology and Physiology, 28(1-2), 95-99. https://doi.org/10.1046/j.14401681.2001.03413.x

Benarroch, E. E. (1993). The central autonomic network: Functional organization, dysfunction, and perspective. Mayo Clinic Proceedings, 68(10), 988-1001. https://doi.org/10.1016 /S0025-6196(12)62272-1

Boehme, A. K., Esenwa, C., \& Elkind, M. S.V. (2017). Stroke risk factors, genetics, and prevention. Circulation Research, 120(3), $\quad 472-495 . \quad$ https://doi.org/10.1161 /CIRCRESAHA.116.308398

Briet, M., \& Schiffrin, E. L. (2013). Vascular actions of aldosterone. Journal of Vascular Research, 50(2), 89-99. https://doi.org/10.1159/000345243

Brillon, D. J., Zheng, B., Campbell, R. G., \& Matthews, D. E. (1995). Effect of cortisol on energy expenditure and amino acid metabolism in humans. American Journal of PhysiologyEndocrinology and Metabolism, 268(3), E501-E513. https://doi.org/10.1152/ajpendo.1995.268.3.E501

Brown, E. G., Gallagher, S., \& Creaven, A.-M. (2018). Loneliness and acute stress reactivity: A systematic review of psychophysiological studies. Psychophysiology, 55(5), e13031. https://doi.org/10.1111/psyp.13031

Bruno, R. M., Di Pilla, M., Ancona, C., Sørensen, M., Gesi, M., Taddei, S., Munzel, T., \& Virdis, A. (2017). Environmental Factors and Hypertension. Current Pharmaceutical Design, 23(22), 3239-3246. $\quad$ https://doi.org/10.2174 $/ 1381612823666170321162233$
Cogiamanian, F., Brunoni, A. R., Boggio, P. S., Fregni, F., Ciocca, M., \& Priori, A. (2010). Non-invasive brain stimulation for the management of arterial hypertension. Medical Hypotheses, 74(2), 332-336. https://doi.org/10.1016/j.mehy.2009.08.037

Costa Vital, J. E., de Morais Nunes, A., Souza de Albuquerque Cacique New York, B., Araujo de Sousa, B. D., Nascimento, M. F., Formiga, M. F., \& Fernandes, A. T. N. S. F. (2021). Biofeedback therapeutic effects on blood pressure levels in hypertensive individuals: A systematic review and metaanalysis. Complementary Therapies in Clinical Practice, 44, 101420. https://doi.org/10.1016/j.ctcp.2021.101420

Cowan, M. J., Pike, K., Burr, R. L., Cain, K. C., \& Narayanan, S. B. (1993). Description of time- and frequency-domain-based measures of heart rate variability in individuals taking antiarrhythmics, beta blockers, calcium channel blockers, and/or antihypertensive drugs after sudden cardiac arrest. Journal of Electrocardiology, 26(Suppl. 1-13).

Crosswell, A. D., \& Lockwood, K. G. (2020). Best practices for stress measurement: How to measure psychological stress in health research. Health Psychology Open, 7(2). https://doi.org $/ 10.1177 / 2055102920933072$

Cuffee, Y., Ogedegbe, C., Williams, N. J., Ogedegbe, G., \& Schoenthaler, A. (2014). Psychosocial risk factors for hypertension: An update of the literature. Current Hypertension Reports, 16(10), 483. https://doi.org/10.1007 /s11906-014-0483-3

Dilgen, J., Tejeda, H. A., \& O'Donnell, P. (2013). Amygdala inputs drive feedforward inhibition in the medial prefrontal cortex. Journal of Neurophysiology, 110(1), 221-229. https://doi.org /10.1152/jn.00531.2012

Duggento, A., Bianciardi, M., Passamonti, L., Wald, L. L., Guerrisi, M., Barbieri, R., \& Toschi, N. (2016). Globally conditioned Granger causality in brain-brain and brain-heart interactions: A combined heart rate variability/ultra-high-field (7 T) functional magnetic resonance imaging study. Philosophical Transactions of the Royal Society A: Mathematical, Physical and Engineering Sciences, 374(2067), 20150185. https://doi.org/10.1098/rsta.2015.0185

Freel, E. M., \& Connell, J. M. C. (2004). Mechanisms of hypertension: The expanding role of aldosterone. Journal of the American Society of Nephrology, 15(8), 1993-2001. https://doi.org/10.1097/01.ASN.0000132473.50966.14

Friedman, B. H., \& Thayer, J. F. (1998). Anxiety and autonomic flexibility: A cardiovascular approach. Biological Psychology, 49(3), 303-323. https://doi.org/10.1016/S03010511(98)00051-9

Gianaros, P. J., \& Wager, T. D. (2015). Brain-body pathways linking psychological stress and physical health. Current Directions in Psychological Science, 24(4), 313-321. https://doi.org/10.1177/0963721415581476

Goit, R. K., \& Ansari, A. H. (2016). Reduced parasympathetic tone in newly diagnosed essential hypertension. Indian Heart Journal, 68(2), 153-157. https://doi.org/10.1016 /j.ihj.2015.08.003

Greenhalgh, J., Dickson, R., \& Dundar, Y. (2010). Biofeedback for hypertension: A systematic review. Journal of Hypertension, 28(4), $\quad 644-652 . \quad$ https://doi.org/10.1097 /HJH.0b013e3283370e20

Guilliams, T. G., \& Edwards, L. (2010). Chronic stress and the HPA axis: Clinical assessment and therapeutic considerations. The Standard, 9(2), 1-12. https://www.pointinstitute.org/wp-content/uploads/2012/10 /standard_v_9.2_hpa_axis.pdf

Harbuz, M. S., \& Lightman, S. L. (1992). Stress and the hypothalamo-pituitary-adrenal axis: Acute, chronic and immunological activation. Journal of Endocrinology, 134(3), 327-339. https://doi.org/10.1677/joe.0.1340327

Heine, H., \& Weiss, M. (1987). Life stress and hypertension. European Heart Journal, 8(Suppl. B), 45-55. https://doi.org /10.1093/eurheartj/8.suppl_B.45 
Hu, G., Barengo, N. C., Tuomilehto, J., Lakka, T. A., Nissinen, A., \& Jousilahti, P. (2004). Relationship of physical activity and body mass index to the risk of hypertension: A prospective study in Finland. Hypertension, 43(1), 25-30. https://doi.org /10.1161/01.HYP.0000107400.72456.19

Kang, H. W., Kim, H. J., Kim, W. Y., Min, W. K., Min, T. J., Lee, Y. S., \& Kim, J. H. (2020). Effects of cranial electrotherapy stimulation on preoperative anxiety and blood pressure during anesthetic induction in patients with essential hypertension. Journal of International Medical Research, 48(8), 300060520939370 . https://doi.org/10.1177 10300060520939370

Khani, S., \& Tayek, J. A. (2001). Cortisol increases gluconeogenesis in humans: Its role in the metabolic syndrome. Clinical Science, 101(6), 739-747. https://doi.org $/ 10.1042 / c s 20010180$

Klabunde, R. E. (2021). Cardiovascular physiology concepts (3rd ed.). Netherlands: Wolters Kluwer.

Komesaroff, P. A., Funder, J. W., \& Fuller, P. J. (1994). 6 Mineralocorticoid resistance. Baillière's Clinical Endocrinology and Metabolism, 8(2), 333-355. https://doi.org/10.1016 /s0950-351x(05)80256-3

Kushibiki, M., Yamada, M., Oikawa, K., Tomita, H., Osanai, T., \& Okumura, K. (2007). Aldosterone causes vasoconstriction in coronary arterioles of rats via angiotensin II type-1 receptor: Influence of hypertension. European Journal of Pharmacology, 572(2-3), 182-188. https://doi.org/10.1016 /j.ejphar.2007.06.017

Landman, G. W. D., Drion, I., van Hateren, K. J. J., van Dijk, P. R., Logtenberg, S. J. J., Lambert, J., Groenier, K. H., Bilo, H. J. G., \& Kleefstra, N. (2013). Device-guided breathing as treatment for hypertension in type 2 diabetes mellitus: A randomized, double-blind, sham-controlled trial. JAMA Internal Medicine, 173(14), 1346-1350. https://doi.org /10.1001/jamainternmed.2013.6883

LeDoux, J. E., Iwata, J., Cicchetti, P., \& Reis, D. J. (1988). Different projections of the central amygdaloid nucleus mediate autonomic and behavioral correlates of conditioned fear. The Journal of Neuroscience, 8(7), 2517-2529. https://doi.org/10.1523/JNEUROSCI.08-07-02517.1988

Lehrer, P. M., \& Gevirtz, R. (2014). Heart rate variability biofeedback: How and why does it work? Frontiers in Psychology, 5, 756. https://doi.org/10.3389/fpsyg.2014.00756

Liao, D., Cai, J., Barnes, R. W., Tyroler, H. A., Rautaharju, P., Holme, I., \& Heiss, G. (1996). Association of cardiac autonomic function and the development of hypertension: The ARIC study. American Journal of Hypertension, 9(12), 11471156. https://doi.org/10.1016/s0895-7061(96)00249-x

Linden, W., \& Chambers, L. (1994). Clinical effectiveness of nondrug treatment for hypertension: A meta-analysis. Annals of Behavioral Medicine, 16(1), 35-45. https://doi.org/10.1093 /abm/16.1.35

Liu, M.-Y., Li, N., Li, W. A., \& Khan, H. (2017). Association between psychosocial stress and hypertension: A systematic review and meta-analysis. Neurological Research, 39(6), 573-580. https://doi.org/10.1080/01616412.2017.1317904

Lynch, S. M., Ward, M., McNulty, H., Angel, C. Z., Horigan, G., Strain, J. J., Purvis, J., Tackett, M., \& McKenna, D. J. (2020). Serum levels of miR-199a-5p correlates with blood pressure in premature cardiovascular disease patients homozygous for the MTHFR 677C > T polymorphism. Genomics, 112(1), 669676. https://doi.org/10.1016/j.ygeno.2019.04.019

Mann, S. J. (2012). Psychosomatic research in hypertension: The lack of impact of decades of research and new directions to consider. The Journal of Clinical Hypertension, 14(10), 657664. https://doi.org/10.1111/j.1751-7176.2012.00686.x

McGrady, A. (2010). The effects of biofeedback in diabetes and essential hypertension. Cleveland Clinic Journal of Medicine, 77(7 Suppl. 3), S68-S71. https://doi.org/10.3949 /ccjm.77.s3.12
Mohammadi, R., Javanmard, G. H., Alipour, A., \& Zare, H. (in press). Effects of mindful breath awareness and muscle relaxation and transcranial electrical stimulation techniques on improving blood pressure status in patients with type 2 diabetes. EXPLORE. https://doi.org/10.1016 /j.explore.2021.05.002

Mussalo, H., Vanninen, E., Ikäheimo, R., Laitinen, T., Laakso, M., Länsimies, E., \& Hartikainen, J. (2001). Heart rate variability and its determinants in patients with severe or mild essential hypertension. Clinical Physiology, 21(5), 594-604. https://doi.org/10.1046/j.1365-2281.2001.00359.x

Nagele, E., Jeitler, K., Horvath, K., Semlitsch, T., Posch, N., Herrmann, K. H., Grouven, U., Hermanns, T., Hemkens, L. G., \& Siebenhofer, A. (2014). Clinical effectiveness of stressreduction techniques in patients with hypertension: Systematic review and meta-analysis. Journal of Hypertension, 32(10), 1936-1944. https://doi.org/10.1097 /HJH.0000000000000298

Nakao, M., Yano, E., Nomura, S., \& Kuboki, T. (2003). Blood pressure-lowering effects of biofeedback treatment in hypertension: A meta-analysis of randomized controlled trials. Hypertension Research, 26(1), 37-46. https://doi.org/10.1291 /hypres.26.37

Napadow, V., Dhond, R., Conti, G., Makris, N., Brown, E. N., \& Barbieri, R. (2008). Brain correlates of autonomic modulation: Combining heart rate variability with fMRI. Neurolmage, 42(1), 169-177. https://doi.org/10.1016 /j.neuroimage.2008.04.238

Natarajan, N., Balakrishnan, A. K., \& Ukkirapandian, K. (2014). A study on analysis of Heart Rate Variability in hypertensive individuals. International Journal of Biomedical and Advance Research, 5(2), 109-111. https://doi.org/10.7439 /ijbar.v5i2.659

Nolan, R. P., Floras, J. S., Harvey, P. J., Kamath, M. V., Picton, P. E., Chessex, C., Hiscock, N., Powell, J., Catt, M., Hendrickx, H., Talbot, D., \& Chen, M. H. (2010). Behavioral neurocardiac training in hypertension: A randomized, controlled trial. Hypertension, 55(4), 1033-1039. https://doi.org/10.1161/HYPERTENSIONAHA.109.146233

Ornosa-Martín, G., Fernandez-Ballart, J. D., Ceruelo, S., Ríos, L., Ueland, P. M., Meyer, K., \& Murphy, M. M. (2020). Homocysteine, the methylenetetrahydrofolate reductase 677C > T polymorphism and hypertension: Effect modifiers by lifestyle factors and population subgroups. British Journal of Nutrition, 124(1), 69-79. https://doi.org/10.1017 /S0007114520000793

Pal, G. K., Adithan, C., Amudharaj, D., Dutta, T. K., Pal, P., Nandan, P. G., \& Nanda, N. (2011). Assessment of sympathovagal imbalance by spectral analysis of heart rate variability in prehypertensive and hypertensive patients in Indian population. Clinical and Experimental Hypertension, 33(7), $\quad 478-483 . \quad$ https://doi.org/10.3109 /10641963.2010.549275

Palomba, D., Ghisi, M., Scozzari, S., Sarlo, M., Bonso, E., Dorigatti, F., \& Palatini, P. (2011). Biofeedback-assisted cardiovascular control in hypertensives exposed to emotional stress: A pilot study. Applied Psychophysiology and Biofeedback, 36(3), 185-192. https://doi.org/10.1007/s10484011-9160-3

Park, A. T., Leonard, J. A., Saxler, P. K., Cyr, A. B., Gabrieli, J. D. E., \& Mackey, A. P. (2018). Amygdala-medial prefrontal cortex connectivity relates to stress and mental health in early childhood. Social Cognitive and Affective Neuroscience, 13(4), 430-439. https://doi.org/10.1093/scan/nsy017

Player, M. S., \& Peterson, L. E. (2011). Anxiety disorders, hypertension, and cardiovascular risk: A review. The International Journal of Psychiatry in Medicine, 41(4), 365377. https://doi.org/10.2190/PM.41.4.f

Podzolkov, V. I., Mel'nikova, T. S., Suvorova, I. A., Churganova, L. I., \& Starovoĭtova, S. P. (1992). [Cranial 
electrostimulation-A new nondrug method of treating the initial stage of hypertension]. Terapevticheskii Arkhiv, 64(1), 24-27.

Poskotinova, L. V., Demin, D. B., Krivonogova, E. V., Dieva, M. N., \& Khasnova, N. M. (2013). [The success of heart rate variability biofeedback parameters in persons with different levels of blood pressure]. Vestnik Rossiiskoi Akademii Meditsinskikh Nauk, 7, 20-23.

Saha, S., Drinkhill, M. J., Moore, J. P., \& Batten, T. F. C. (2005). Central nucleus of amygdala projections to rostral ventrolateral medulla neurones activated by decreased blood pressure. The European Journal of Neuroscience, 21(7), 1921-1930. https://doi.org/10.1111/j.1460-9568.2005.04023.x

Schroeder, E. B., Liao, D., Chambless, L. E., Prineas, R. J., Evans, G. W., \& Heiss, G. (2003). Hypertension, blood pressure, and heart rate variability: The Atherosclerosis Risk in Communities (ARIC) study. Hypertension, 42(6), 11061111. https://doi.org/10.1161/01.HYP.0000100444.71069.73

Schumann, A., de la Cruz, F., Köhler, S., Brotte, L., \& Bär, K.-J. (2021). The influence of heart rate variability biofeedback on cardiac regulation and functional brain connectivity. Frontiers in Neuroscience, 15, 691988. https://doi.org/10.3389 /fnins.2021.691988

Selye, H. (1956). The Stress of Life. New York, NY: McGraw-Hill.

Shekhar, A., Sajdyk, T. J., Gehlert, D. R., \& Rainnie, D. G. (2003). The amygdala, panic disorder, and cardiovascular responses. Annals of the New York Academy of Sciences, 985(1), 308325. https://doi.org/10.1111/j.1749-6632.2003.tb07090.x

Siepmann, T., Ohle, P., Sedghi, A., Simon, E., Arndt, M., Pallesen, L.-P., Ritschel, G., Barlinn, J., Reichmann, H. Puetz, V., \& Barlinn, K. (2021). Randomized sham-controlled pilot study of neurocardiac function in patients with acute ischaemic stroke undergoing heart rate variability biofeedback. Frontiers in Neurology, 12, 669843. https://doi.org/10.3389/fneur.2021.669843

Singh, A., Babyak, M. A., Nolan, D. K., Brummett, B. H., Jiang, R., Siegler, I. C., Kraus, W. E., Shah, S. H., Williams, R. B., \& Hauser, E. R. (2015). Gene by stress genome-wide interaction analysis and path analysis identify $E B F 1$ as a cardiovascular and metabolic risk gene. European Journal of Human Genetics, 23(6), 854-862. https://doi.org/10.1038 lejhg.2014.189

Singh, J. P., Larson, M. G., Tsuji, H., Evans, J. C., O'Donnell, C J., \& Levy, D. (1998). Reduced heart rate variability and newonset hypertension: Insights into pathogenesis of hypertension: the Framingham Heart Study. Hypertension, 32(2), 293-297. https://doi.org/10.1161/01.hyp.32.2.293

Smith, M. D., \& Maani, C. V. (2020). Norepinephrine. In StatPearls [Internet]. Treasure Island, FL: StatPearls Publishing. https://www.ncbi.nlm.nih.gov/books/NBK537259/

Sparrenberger, F., Cichelero, F. T., Ascoli, A. M., Fonseca, F. P., Weiss, G., Berwanger, O., Fuchs, S. C., Moreira, L. B., \& Fuchs, F. D. (2009). Does psychosocial stress cause hypertension? A systematic review of observational studies.
Journal of Human Hypertension, 23(1), 12-19. https://doi.org/10.1038/jhh.2008.74

Špinar, J. (2012). Hypertension and ischemic heart disease. Cor et Vasa, 54(11), e433-e438. https://doi.org/10.1016 /j.crvasa.2012.11.002

Task Force of the European Society of Cardiology the North American Society of Pacing Electrophysiology. (1996). Heart rate variability: Standards of measurement, physiological interpretation, and clinical use. Circulation, 93(5), 1043-1065. https://doi.org/10.1161/01.CIR.93.5.1043

Thayer, J. F., Hansen, A. L., Saus-Rose, E., \& Johnsen, B. H. (2009). Heart rate variability, prefrontal neural function, and cognitive performance: The neurovisceral integration perspective on self-regulation, adaptation, and health. Annals of Behavioral Medicine, 37(2), 141-153. https://doi.org /10.1007/s12160-009-9101-z

Thayer, J. F., Yamamoto, S. S., \& Brosschot, J. F. (2010). The relationship of autonomic imbalance, heart rate variability and cardiovascular disease risk factors. International Journal of Cardiology, 141(2), 122-131. https://doi.org/10.1016 jj.ijcard.2009.09.543

Tsigos, C., \& Chrousos, G. P. (2002). Hypothalamic-pituitaryadrenal axis, neuroendocrine factors and stress. Journal of Psychosomatic Research, 53(4), 865-871. https://doi.org /10.1016/S0022-3999(02)00429-4

Vos, T., Lim, S. S., Abbafati, C., Abbas, K. M., Abbasi, M., Abbasifard, M., Abbasi-Kangevari, M., Abbastabar, H., AbdAllah, F., Abdelalim, A., Abdollahi, M., Abdollahpour, I., Abolhassani, H., Aboyans, V., Abrams, E. M., Abreu, L. G., Abrigo, M. R. M., Abu-Raddad, L. J., Abushouk, A. I., Acebedo, A., ... Murray, C. J. L. (2020). Global burden of 369 diseases and injuries in 204 countries and territories, 19902019: A systematic analysis for the Global Burden of Disease Study 2019. The Lancet, 396(10258), 1204-1222. https://doi.org/10.1016/S0140-6736(20)30925-9

Wajngarten, M., \& Silva, G. S. (2019). Hypertension and stroke: Update on treatment. European Cardiology Review, 14(2), 111-115. https://doi.org/10.15420/ecr.2019.11.1

Xanthakis, V., \& Vasan, R. S. (2013). Aldosterone and the risk of hypertension. Current Hypertension Reports, 15(2), 102-107. https://doi.org/10.1007/s11906-013-0330-y

Xu, Y., Day, T. A., \& Buller, K. M. (1999). The central amygdala modulates hypothalamic-pituitary-adrenal axis responses to systemic interleukin-1 $\beta$ administration. Neuroscience, 94(1), 175-183. https://doi.org/10.1016/S0306-4522(99)00311-5

Ziegler, G., Dahnke, R., Yeragani, V. K., \& Bär, K.-J. (2009). The relation of ventromedial prefrontal cortex activity and heart rate fluctuations at rest. The European Journal of Neuroscience, 30(11), 2205-2210. https://doi.org/10.1111 /j.1460-9568.2009.07008.x

Received: July 14, 2021

Accepted: September 10, 2021

Published: September 30, 2021 